\title{
Effects of Limonoids from Cipadessa fruticosa on Fall Armyworm
}

\author{
Andreia P. Matos, Ana C. Leite, Luciane G. Batista-Pereira, Paulo C. Vieira, \\ João B. Fernandes*, and Maria Fátima das G. F. da Silva \\ Departamento de Química, Universidade Federal de São Carlos, Caixa Postal 676, \\ CEP 13565-905, São Carlos - SP, Brazil. Fax: +55-16-33 51-83 50. \\ E-mail:djbf@power.ufscar.br \\ * Author for correspondence and reprint requests \\ Z. Naturforsch. 64c, 441-446 (2009); received October 14/December 9, 2008
}

Six mexicanolide limonoids isolated from the dichloromethane extract of the fruits of Cipadessa fruticosa Blume (Meliaceae) were evaluated against Spodoptera frugiperda (J. E. Smith). Gedunin was used as a positive control. When incorporated into an artificial diet of neonates at $50.0 \mathrm{mg} \mathrm{kg}^{-1}$, febrifugin A showed $73.3 \%$ mortality. All the compounds showed moderate insecticidal activity, except for ruageanin $\mathrm{A}$, when compared with the control. Febrifugin also showed growth inhibition and antifeedant activities (at $100.0 \mathrm{mg} \mathrm{kg}^{-1}$ ). The correlation between the insecticidal activity of the isolated compounds and their chemical structure was discussed.

Key words: Limonoids, Cipadessa fruticosa, Spodoptera frugiperda

\section{Introduction}

Insecticides of botanical origin may offer a source of agents for pest control and may be an efficient alternative to persistent synthetic insecticides. The increasing interest in the possible application of secondary metabolites for pest management has directed the investigations toward the search for new sources of biologically active natural products with low mammalian toxicity, lack of neurotoxic action, low persistence in the environment, biodegradability, and no development of resistance by insect pest (Céspedes et al., 2000). After the isolation of azadirachtin, an effective insect antifeedant against the desert locust (Butterworth and Morgan, 1971), from neem seeds, several limonoids from the order Rutales have been screened for their insect antifeedant activity.

Limonoids are modified triterpenes. They present a wide range of biological activities, including insect-antifeeding and growth-regulating properties, a variety of medicinal effects on animals and humans, and antifungal, bactericidal and antiviral properties (Champagne et al., 1992).

Cipadessa fruticosa Blume (Meliaceae) is widely cultivated in the southwest of China. This plant has been reported to contain ent-clerodane and labdane diterpenoids (Rojatkar and Nagasampagi, 1994; Rojatkar et al., 1994), limonoids, ster- ols, sesquiterpenoids, heneicosene derivates and one coumarin (Luo et al., 2000, 2001). Flavonoid glycosides (Liang et al., 1991, 1994) were isolated from C. cinerascens, and C. boivinina yielded sterols (Mulholland et al., 1999).

In the present paper, mexicanolide-type limonoids, cipadesin A (1), ruageanin A (2), cipadesin (3), febrifugin (4), febrifugin A (5) and khayasin T (6), previously isolated from $C$. fruticosa (Leite $e t$ al., 2005; Fig. 1), were examined on the fall armyworm, Spodoptera frugiperda (J. E. Smith) (Lepidoptera: Noctuidae). S. frugiperda is a major pest of many crops in the Americas and one of the most important pests of tropical maize, causing up to $34 \%$ reduction in the overall productivity of this crop in Brazil (Cruz et al., 1996).

\section{Material and Methods}

\section{Plant material}

The fruits of Cipadessa fruticosa Blume were collected in Viçosa, Minas Gerais, Brazil, and a voucher specimen (110.664) is deposited in the Herbarium of Instituto de Ciências Biológicas, USP, São Paulo, Brazil.

\section{Extraction and isolation of compounds}

The powdered air-dried fruits $(990 \mathrm{~g})$ of $C$. fruticosa were subsequently extracted with hexane, $\mathrm{CH}_{2} \mathrm{Cl}_{2}$ and $\mathrm{MeOH}$. The conc. $\mathrm{CH}_{2} \mathrm{Cl}_{2}$ ex- 
<smiles>[R]C(=O)[R]C([R])[R]</smiles>

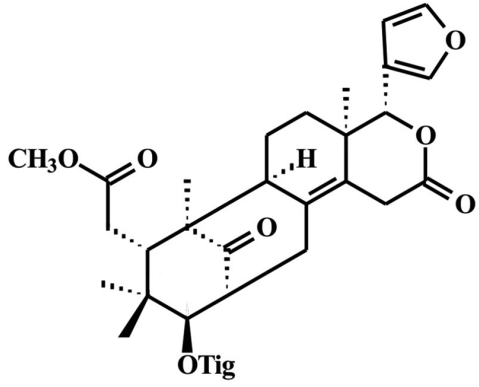

6<smiles>CC(=O)OC1CC2C(C)(C)C(=O)C=C[C@]2(C)C2CC[C@]3(C)[C@@H](c4ccoc4)OC(=O)[C@@H]4O[C@]43[C@]12C</smiles>

7

Fig. 1. Chemical structures of limonoids 1-6 from Cipadessa fruticosa and gedunin (7).

tract $(10.9 \mathrm{~g})$ was submitted to vacuum chromatography over silica gel using a hexane $/ \mathrm{CH}_{2} \mathrm{Cl}_{2} /$ EtOAc/MeOH gradient. The ethyl acetate-soluble fraction $(2.3 \mathrm{~g})$, rich in limonoids, was chromatographed on silica gel, eluting with a hexane/ $\mathrm{CH}_{2} \mathrm{Cl}_{2}$ /acetone gradient to give 8 fractions (A$\mathrm{H})$. Fraction $\mathrm{C}$ was fractionated as above, using a hexane/EtOAc gradient, affording 11 fractions. Fraction C-4 was eluted with a hexane $/ \mathrm{CH}_{2} \mathrm{Cl}_{2} / \mathrm{ac}$ etone gradient to give 6 fractions (C-4.1-C-4.6). Fraction C-4.2 was purified by HPLC (detection at $\lambda=240 \mathrm{~nm}$ ), using hexane/iso-propanol (9:1)

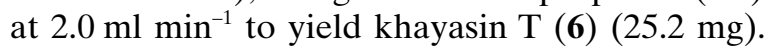
Fraction C-6 was twice chromatographed on silica gel, eluting with hexane $/ \mathrm{CH}_{2} \mathrm{Cl}_{2}$ /acetone (6:3:1) to give cipadesin A (1) (8.5 mg) and cipadesin (3) $(19.4 \mathrm{mg})$. Fraction D was chromatographed as above, using a hexane/EtOAc gradient, to afford 4 fractions. Fraction D-3 was twice chromatographed with a hexane $/ \mathrm{CH}_{2} \mathrm{Cl}_{2} /$ acetone gradient yielding a fraction containing compound $\mathbf{2}$, which was purified by HPLC on silica gel (detection at $\lambda=220 \mathrm{~nm}$ ), using hexane/iso-propanol (85:15) with a flow rate of $1.5 \mathrm{ml} \mathrm{min}^{-1}$, to yield ruageanin A (2) (9.3 mg). Fraction E was twice subjected to column chromatography over silica gel, eluting with a hexane $/ \mathrm{CH}_{2} \mathrm{Cl}_{2} /$ acetone gradient, affording 4 fractions. Fraction E-3 was purified by HPLC over a polymeric column (detection at $\lambda=240 \mathrm{~nm}$ ), using hexane/iso-propanol (8:2) at $2.0 \mathrm{ml} \mathrm{min}{ }^{-1}$, to give febrifugin $\mathrm{A}(\mathbf{5})(4.7 \mathrm{mg})$ and febrifugin (4) (40.3 mg). ${ }^{1} \mathrm{H}$ NMR, ${ }^{13} \mathrm{C}$ NMR and other physical data of cipadesin A (1), ruageanin A (2), cipadesin (3), febrifugin (4), febrifugin A (5) and khayasin $\mathrm{T}$ (6) were given by Leite et al. (2005). Gedunin (7) was a gift from Dr. José Realino de Paula.

\section{Biological activity}

Larvae of Spodoptera frugiperda (J. E. Smith) were obtained from the Insect Bioassay Laboratory of Universidade Federal de São Carlos, Bra- 
zil, and reared on artificial diets (Kasten et al., 1978; Parra, 1986). They were maintained in an incubation chamber at $12 \mathrm{~h}$ light and $12 \mathrm{~h}$ dark, $(70 \pm 5) \%$ relative humidity and $(25 \pm 1){ }^{\circ} \mathrm{C}$. For each treatment and control, 30 neonate larvae of S. frugiperda were used. A solution of limonoid was added to ascorbic acid $(1.56 \mathrm{~g}$; an ingredient of the diet). After evaporation, the mixture was incorporated to the artificial diet in which bean and wheat germ were the basic ingredients (Kasten et $a l ., 1978)$ at final contents of 1.0, 10.0, 50.0 and $100.0 \mathrm{mg} \mathrm{kg}^{-1}$ for the limonoids cipadesin A (1), cipadesin (3) and febrifugin (4); for the limonoids ruageanina $A(2)$, febrifugin $A(5)$ and khayasin $\mathrm{T}$ (6) final contents of 1.0, 10.0 and $50.0 \mathrm{mg} \mathrm{kg}^{-1}$ were utilized. The diet for the control was prepared similarly with no limonoid. Gedunin (7) was utilized as positive control (Céspedes et al., $2005)$. The diets were placed in previously sterilized glass tubes $(8.5 \mathrm{~cm} \times 2.5 \mathrm{~cm})$, into which larvae of $S$. frugiperda were introduced individually. The obtained pupae were weighed after pupation and were transferred to plastic cups, where they were kept until the emergence of adults. Daily observations were made and the following parameters were evaluated: duration of larval and pupal phases; weight of pupae, and percentage of dead insects (mortality) at the end of each phase and of the life cycle (larva to emergence of adult).

\section{Statistics}

Data were submitted to an analysis of variance (ANOVA; Zar, 1984) and the averages were compared applying the Tukey test $(P \leq 0.05)$. Each tube containing one insect, independent of the development phase, was considered as one replicate; therefore, the number of replicates was different for each treatment. For evaluation of the mortality of the larval and pupal phases, the experimental unit was constituted by the mean of five tubes with one larva each, with six replications by treatment.

\section{Results and Discussion}

Significant differences were observed for the mortality of larvae, pupae, and total life cycle (larva to emergence of adult) of $S$. frugiperda by increasing the content of febrifugin A (5) in the diet (Table I and Fig. 2). The mortality varied from $10.0 \%$ (control) to $20.0 \%, 46.7 \%$, and $50.0 \%$ (in the larval phase for $1.0,10.0$ and $50.0 \mathrm{mg} \mathrm{kg}^{-1}$, respectively). In the pupal phase, the mortality varied from $0 \%$ (control) to $6.7 \%\left(1.0 \mathrm{mg} \mathrm{kg}^{-1}\right), 6.7 \%$ $\left(10.0 \mathrm{mg} \mathrm{kg}^{-1}\right)$ and $23.3 \%\left(50.0 \mathrm{mg} \mathrm{kg}^{-1}\right)$. These variations interfered significantly with the total cycle mortality and the observed average mortality varied from $10.0 \%$ (control) to $73.3 \%\left(50.0 \mathrm{mg} \mathrm{kg}^{-1}\right)$.

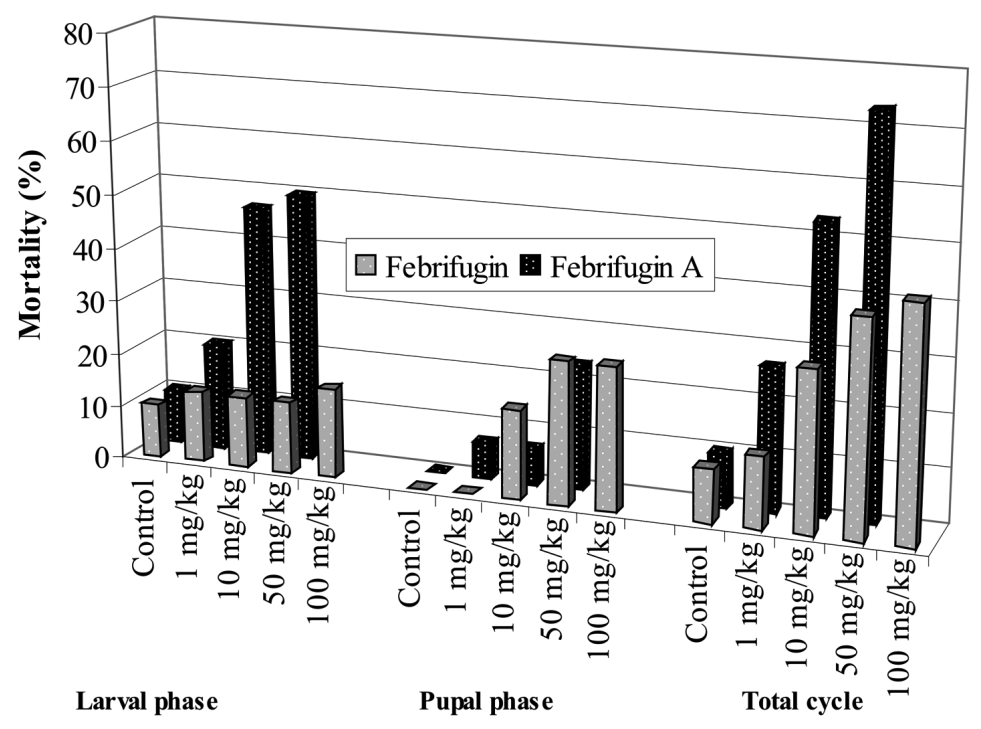

Fig. 2. Mortality of larval and pupal stages and total cycle dependent on febrifugin (4) and febrifugin A (5) administered with the artificial diet of Spodoptera frugiperda. 


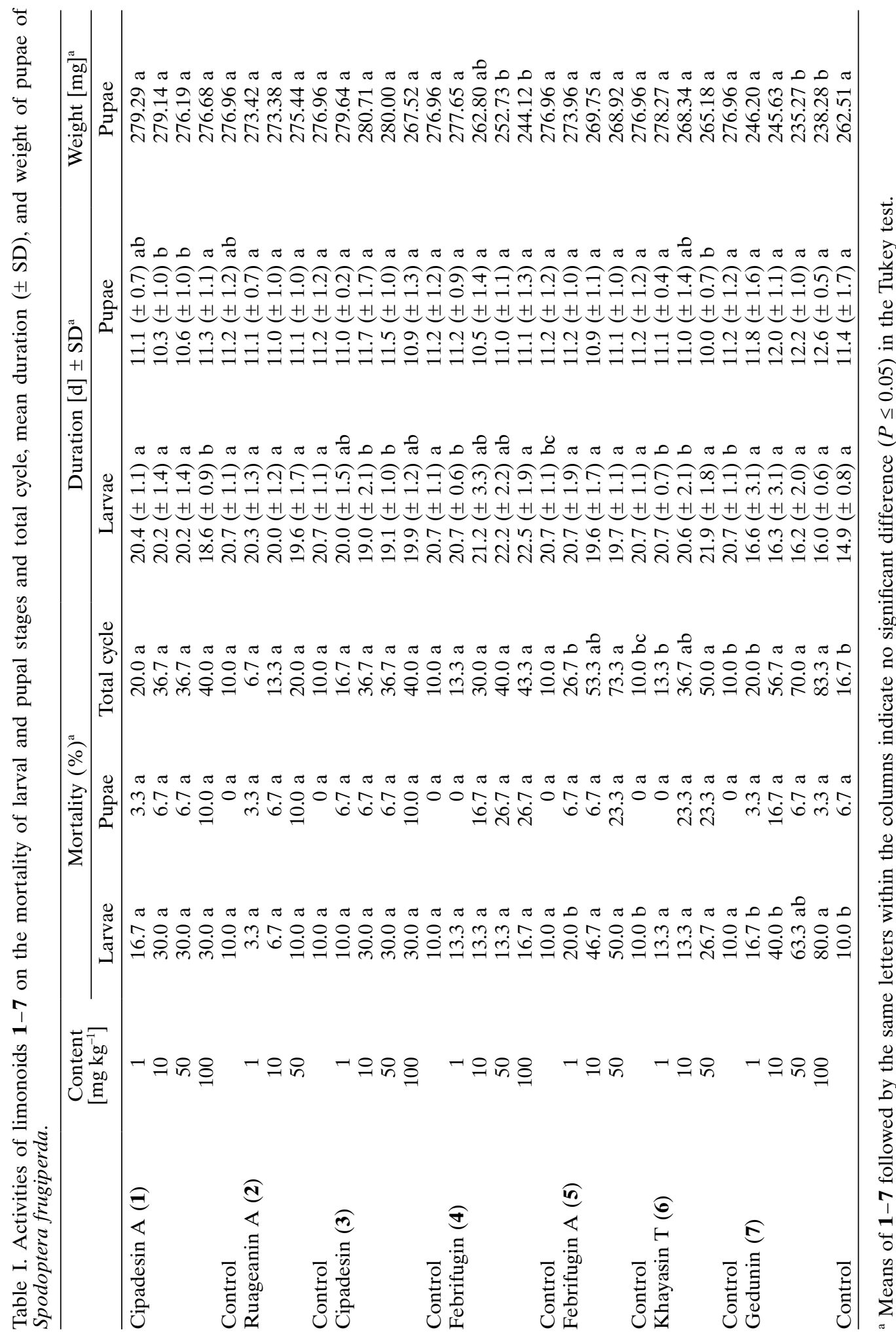


Nevertheless, febrifugin A (5) showed the highest insecticidal activity at $50.0 \mathrm{mg} \mathrm{kg}^{-1}$ with $73.3 \%$ mortality. Besides, the larvae treated with khayasin T (6) showed high mortality of the total cycle with $50.0 \%$ at $50.0 \mathrm{mg} \mathrm{kg}^{-1}$ when compared with the control $(10 \%)$.

The compounds cipadesin A (1), ruageanin A (2), cipadesin (3) and febrifugin (4) showed no significant total cycle mortalities $(\leq 40 \%)$ at $50.0 \mathrm{mg} \mathrm{kg}^{-1}$ when compared with the control $(10 \%)$.

The high insecticidal activity of febrifugin A (5) reinforces the observation of Suresh et al. (2002) that a hydroxy group at C-23 and a carbonyl group at C-21 are important for the activity. These authors demonstrated that the limonoids with intact and seco rings and an intact furan ring show a marked increase in the antifeedant activity when compared with the furan ring oxygenated at C-21 and C-23. Céspedes et al. (2000) suggested that the presence of an oxygenated function at C-23 is necessary for the activity displayed by photogedunin acetate $\mathrm{C}-23$ epimers and photogedunin C-23 epimers against $S$. frugiperda. These data are confirmed when compared with the moderate mortality showed in the total cycle of larvae treated with febrifugin (4) (Fig. 2).

The effect of mexicanolide-type limonoids on the mortality of $S$. frugiperda verified in our study was similar to that of the humilinolides against European corn borer (ECB), Ostrinia nubilalis Hübner (Lepidoptera: Pyralidae), demonstrated by Jimenez et al. (1997).

A short prolongation of the larval phase was observed for larvae treated with khayasin $\mathrm{T}(\mathbf{6})$ and febrifugin (4) at $50.0 \mathrm{mg} \mathrm{kg}^{-1}$, for 1.2 and 1.8 days, respectively, when compared with the control. These data suggest that these compounds are acting as larval growth inhibitors. In contrast, the larvae treated with cipadesin A (1) at $100.0 \mathrm{mg} \mathrm{kg}^{-1}$ and cipadesin (3) at 10,50 and $100.0 \mathrm{mg} \mathrm{kg}^{-1}$ showed shortened larval phases of 2.1 and 1.7, 1.6 and 0.8 days, respectively (Table I).
A significant reduction $(277-244 \mathrm{mg}$ ) in the pupal weight of $S$. frugiperda treated with febrifugin (4) was observed compared with the control (Table I). This reduction in the pupal weight suggests that $\mathbf{4}$ acts as antifeedant. Adults emerging from low weight pupae could be more debilitated and would have a lower capacity of competition for vital activities than individuals from healthy pupae (Batista-Pereira et al., 2002).

Tanzubil and McCaffery (1990) observed that larvae treated with low doses of azadirachtin produced pupae of weights comparable to controls, suggesting that they did not experience any severe feeding inhibition. This was also observed for khayasin $T(\mathbf{6})$. Similar cases of alteration in growth without feeding inhibition have been reported by other workers (Seiber and Rembold, 1983; Gaaboub and Hayes, 1984).

A short reduction in the pupal phase was observed for larvae fed with artificial diet treated with cipadesin $\mathrm{A}(\mathbf{1})$ at 10 and $50.0 \mathrm{mg} \mathrm{kg}^{-1}$ and khayasin $\mathrm{T}(\mathbf{6})$ at $50.0 \mathrm{mg} \mathrm{kg}^{-1}$ for $0.9,0.6$ and 1.2 days, respectively, when compared with the control.

Only febrifugin A (5) showed activities comparable to gedunin (7), which suggests potential for further development of these materials for the control of $S$. frugiperda. Febrifugin A (5) showed the highest insecticidal activity at $50.0 \mathrm{mg} \mathrm{kg}^{-1}$. Febrifugin (4) besides a moderate insecticidal activity also demonstrated growth inhibition and antifeedant activity at $100.0 \mathrm{mg} \mathrm{kg}^{-1}$.

\section{Acknowledgements}

The authors would like to thank the Conselho Nacional de Desenvolvimento Científico e Tecnológico (CNPQ), Coordenação Pessoal de Nível Superior (CAPES), and Fundação de Amparo à Pesquisa do Estado de São Paulo (FAPESP) for financial support and scholarships (CNPQ), and Dr. José Realino de Paula, Universidade Federal de Goías, Brazil, for gedunin supply. 
Batista-Pereira L. G., Petacci F., Fernandes J. B., Corrêa A. G., Vieira P. C., Da Silva M. F. G. F., and Malaspina O. (2002), Biological activity of astilbin from Dimorphandra mollis against Anticarsia gemmatalis and Spodoptera frugiperda. Pest. Manag. Sci. 58, $503-507$.

Butterworth J. H. and Morgan E. D. (1971), Investigation of the locust feeding inhibition of the seeds of the neem tree Azadirachta indica. J. Insect Physiol. 17, 969-977.

Céspedes C. L., Calderón J. S., Lina L., and Aranda E. (2000), Growth inhibitory effects on fall armyworm Spodoptera frugiperda of some limonoids isolated from Cedrela spp. (Meliaceae). J. Agric. Food Chem. 48, 1903-1908.

Céspedes C. L., Salazar J. R., Martínez M., and Aranda E. (2005), Insect growth regulatory effects of some extracts and sterols from Myrtillocactus geometrizans (Cactaceae) against Spodoptera frugiperda and Tenebrio molitor. Phytochemistry 66, 2481-2493.

Champagne D. E., Koul O., Isman M. B., Scudder G. G. E., and Towers G. H. N. (1992), Biological activity of limonoids from the Rutales. Phytochemistry 31, $377-394$

Cruz I., Oliveira L. J., and Vasconcelos C. A. (1996), Efeito do nível de saturação de alumínio em solos ácidos sobre os danos de Spodoptera frugiperda (JE Smith) em milho. Anais Soc. Entomol. Brasil. 25, 293-297.

Gaaboub A. I. and Hayes D. K. (1984), Effects of larval treatment with azadirachtin, a moulting inhibition component of the neem tree on reproductive capacity of the fly Musca autumnalis. Environ. Entomol. 13, 1639-1643.

Jimenez A., Mata R., Pereda-Miranda R., Calderón J., Isman M. B., Nicol R., and Arnason J. T. (1997), Insecticidal limonoids from Swietenia humilis and $\mathrm{Ce}$ drela salvadorensis. J. Chem. Ecol. 23, 1225-1234.

Kasten P. J. R., Precetti A. A. C. M., and Parra J. R. P. (1978), Dados biológicos comparativos de Spodoptera frugiperda (JE Smith, 1797) em duas dietas artificiais e substrato natural. Rev. Agric. 53, 68-78.
Leite A. C., Fernandes J. B., Da Silva M. F. G. F., and Vieira P. C. (2005), Limonoids from Cipadessa fruticosa. Z. Naturforsch. 60c, 351-355.

Liang L., Zhong C. C., and Xiao Z. Y. (1991), Chemical components from leaves of greyhair Cipadessa ( $\mathrm{C} i$ padessa cinerascens). Zhongcaoyao 22, 6-8.

Liang L., Zhong C. C., and Xiao Z. Y. (1994), Chemical constituents of leaves of greyhair Cipadessa (Cipadessa cinerascens) (III). Zhongcaoyao 25, 236-237.

Luo X. D., Wu S. H., Ma Y. B., and Wu D. G. (2000), Components of Cipadessa baccifera. Phytochemistry 55, $867-872$.

Luo X. D., Wu S. H., Ma Y. B., and Wu D. G. (2001), Studies on chemical constituents of Cipadessa baccifera. Zhongcaoyao 32, 778-780.

Mulholland D. A., Schwikkard S. L., and Randrianarivelojosoia M. (1999), Limonoids from Astrotrichilia voamatata. Phytochemistry 52, 705-707.

Parra J. R. P. (1986), Criação de insetos para estudos com patógenos. In: Controle microbiano de insetos (Alves S. B., ed.). Editora Manole, São Paulo, Brazil, pp. 348-373.

Rojatkar S. R. and Nagasampagi B. A. (1994), Diterpenes from Cipadessa fruticosa. Phytochemistry 37, 505-507.

Rojatkar S. R., Chiplunkar Y. G., and Nagasampagi B. A. (1994), A diterpene from Cipadessa fruticosa and Grangea maderaspatana. Phytochemistry 37, $1213-1214$

Seiber K. P. and Rembold H. (1983), The effects of azadirachtin on the endocrine control of moulting in $\mathrm{Lo}$ custa migratoria. J. Insect Physiol. 29, 523-527.

Suresh G., Gopalakrishnan G., Wesley S. D., Singh N. D. P., Malathi R., and Rajan S. S. (2002), Insect antifeedant activity of tetranortriterpenoids from the Rutales. A perusal of structural relations. J. Agric. Food Chem. 50, 4484-4490.

Tanzubil P. B. and McCaffery A. R. (1990), Effects of azadirachtin and aqueous neem seed extracts on survival, growth and development of the African armyworm, Spodoptera exempta. Crop Protec. 9, $383-386$.

Zar J. H. (1984), Biostatistical Analysis. Prentice-Hall Inc, Englewood Cliffs, NJ, USA, pp. 179-233. 